\title{
Social Mechanism of Self-Development of Physical Culture
}

\author{
Vasyl Sutula* \\ Kharkiv State Academy of Physical Culture, Ukraine \\ *Corresponding author: Vasyl Sutula, Kharkiv State Academy of Physical Culture, Ukraine. \\ To Cite This Article: : Vasyl Sutula. Social Mechanism of Self-Development of Physical Culture. Am J Biomed Sci \& Res. 2019 - 2(6). AJBSR. \\ MS.ID.000611. DOI: 10.34297/AJBSR.2019.02.000611
}

Received: April 18, 2019 | Published: May 02, 2019

\section{Commentry}

Since man is simultaneously the subject and the object of the process of historical development of society, one can conclude that in society all the diversity of human needs is realized in the form of individual or group activity of people. Such activity creates in society a special relationship between people, which under certain conditions is the basis of the mechanism of their self-organization and leads to the appearance in society of various social phenomena that can be transformed into corresponding social institutions. This process can be described as follows. In an effort to satisfy a particular need, a person enters into relationships with other people who have similar aspirations. Such interaction can lead to the unification of these people in order to jointly obtain the necessary goods and values to meet common needs. It contributes to the formation of social groups, which are characterized by relative integrity and are an independent subject of social action. Thus, based on specific personal needs of a person formed group needs, which, unlike personal, are more stable and more stable. This process - one of the forms of social realization of the natural need of a person belonging to the group.

On the other hand, the association of people into groups leads to the emergence of direct or indirect competing relationships between its members, as well as between the groups they represent, which is the consequence of the implementation of people's individual needs for self-expression. Dedicated to the dialectically contradictory activities of people (on the one hand, the desire to group into groups, and on the other, the desire for self-expression that creates competing relationships between members of the group, as well as between the corresponding groups) is just the basis of the mechanism of self-development of social phenomena. Group needs can be formed, and the process of their satisfaction acquire a systematic character and develop in a social environment only after obtaining proper social assessment. If group needs that have emerged in the process of people's activities to meet personal needs do not receive a positive public assessment, this can lead to a curtailment of the relevant social process, or even to the complete elimination of the proper social base, and therefore the corresponding social phenomenon.
If the social assessment of the social phenomenon that arose as a result of the group's activities to meet common needs is positive then such a phenomenon, and, accordingly, the activities of people, become socially significant. On this basis, a corresponding social institution can be formed, which becomes a special social form of consolidation and a way of carrying out specialized activities of people. It is he (social institute) and ensures the stable functioning of social relations based on the activities of people in the area of meeting common needs, which may mean that such a social phenomenon characterizes one of the basic elements of the culture of society. Personality, group and socially important needs are interdependent. The system of their interconnections is a feedback system. Thus, group needs formed on the ground of personal influence on the latter, defining the specific forms of human activity for their satisfaction (rules of activity, organization and procedure for preparation for it, etc.). Formation of socially important needs though occurs on the basis of group, but this level determines the historical vector of the evolution of social phenomena and processes that arise as a result of people's activities to meet group and personality (primarily social and biosocial) needs.

One can conclude that in a society based on the competitive interaction of people about satisfaction of common needs is formed system of relations, which is self-organizing, which is the basis of the development of the corresponding social phenomenon. From the historical point of view, the mechanism of development of social phenomena, if it is considered as a process of satisfying people's needs, can be represented as a self-regulatory system of social relations, based on the competitive activity of people to meet socially predetermined and biosocial needs. The essence of this phenomenon is that the process of satisfaction of personal and group needs of a person, as already mentioned above, can develop and historically transform only after such activity receives proper public recognition. It is obvious that the opposite is possible, when reducing public interest in the activities of people leads to a decrease in the social significance of the phenomenon that arose on the basis of this activity, which may even lead to its complete disappearance. 
The above-described scheme of self-regulatory process of people's activities on the basis of a competitive relationship between them in essence reflects the process of the emergence and development of socially significant phenomena. What are the various forms of social manifestation of the sphere of activity of people associated with the use of physical exercises that during the cultural-historical process received their own names - physical education, sports, physical fitness (physical recreation) and other forms of social practice related to them? Thus, the social mechanism of self-development of the sphere of activity of people associated with the use of physical exercises, for which the name is used by the term "physical culture", manifests itself in dialectical unity, on the one hand, competing activities of people to meet various needs for exercise, and on the other, a public assessment of such activity. In this process, with the help of a public assessment, selection is made of a variety of social phenomena that arise as a result of the activities of people associated with the use of physical exercises that are relevant to society. 